\title{
Properties of ductile high entropy bulk metallic glass $\mathrm{Cu}_{29} \mathrm{Zr}_{32} \mathrm{Ti}_{15} \mathrm{Al}_{5} \mathrm{Ni}_{19}$
}

\author{
JinHong $\mathrm{Pi}^{1,2} \mathrm{a}^{*}$, XianCong $\mathrm{He}^{1,2 \mathrm{~b}}$ and Yunqiang Bai ${ }^{1,2 \mathrm{c}}$ \\ ${ }^{1}$ School of Materials Engineering, Nanjing Institute of Technology, Nanjing 211167, China \\ 2 Jiangsu Key Laboratory of Advanced Structural Materials and Application Technology, Nanjing \\ 211167, China
}

apijinhong@163.com, bhexiancong@njit.edu.cn , cyunqiang_bai@njit.edu.cn

Keywords: metallic glass; high entropy alloy; compressive strength; modulus; nano indentation Abstract. Bulk metallic glass $\mathrm{Cu}_{29} \mathrm{Zr}_{32} \mathrm{Ti}_{15} \mathrm{Al}_{5} \mathrm{Ni}_{19}$ was successfully prepared in a copper mold with designing idea of high entropy alloys. The compressive strength of glassy $\mathrm{Cu}_{29} \mathrm{Zr}_{32} \mathrm{Ti}_{15} \mathrm{Al}_{5} \mathrm{Ni}_{19}$ is 1673.4MPa. Particular attention should be pay to that it shows a plastic deformation high up to $20 \%$ during compression. According to the nanoindentation analysis, the modulus and the nano-hardness of glassy $\mathrm{Cu}_{29} \mathrm{Zr}_{32} \mathrm{Ti}_{15} \mathrm{Al}_{5} \mathrm{Ni}_{19}$ is up to $103.8 \mathrm{GPa}$ and 7.52GPa, respectively.

\section{Introduction}

Both bulk metallic glasses (BMGs) and high entropy alloys (HEAs) possess excellent mechanical and physical properties combining excellent corrosion resistance ${ }^{[1-2]}$. Reports on glassy $\mathrm{Pd}_{20} \mathrm{Pt}_{20} \mathrm{Cu}_{20} \mathrm{Ni}_{20} \mathrm{P}_{20}$ and $\mathrm{Zn}_{20} \mathrm{Ca}_{20} \mathrm{Sr}_{20} \mathrm{Yb}_{20}\left(\mathrm{Li}_{0.55} \mathrm{Mg}_{0.45}\right)_{20}$ alloys show that new BMGs with a characteristic of HEAs can be found in multi-component systems ${ }^{[1,3]}$. And the concept of high-entropy bulk metallic glasses (HE-BMGs) was put forward. In order to study the similarity and difference between these two kinds of multi-component alloys, series of new HE-BMGs were designed and successfully fabricated in very recently ${ }^{[4-7]}$. However, HE-BMGs are not well studied due to the very limited examples. There remain a plenty of unknown scientific rules and features of HE-BMGs, since the very short history of HE-BMGs.

Considering the atomic size difference plays a very important role in the formation of solid solution phases or bulk metallic glasses ${ }^{[2,4,8]}$ and the high mixing entropy and large negative enthalpy of mixing favor the formation of BMGs, a new HE-BMG $\mathrm{Cu}_{29} \mathrm{Zr}_{32} \mathrm{Ti}_{15} \mathrm{Al}_{5} \mathrm{Ni}_{19}$ was fabricated and investigated by nano-indentation in this paper.

\section{Experimental details}

The master alloy ingot with a nominal chemical composition of $\mathrm{Cu}_{29} \mathrm{Zr}_{32} \mathrm{Ti}_{15} \mathrm{Al}_{5} \mathrm{Ni}_{19}$ (in atomic percentage) was prepared by arc-melting the mixture of pure bulk metals (purity higher than $99.9 \mathrm{wt}$ $\%)$ under high purity argon atmosphere. Then the arc-melted ingot was re-melted and cast into a rod-shaped cavity in a copper mold with a diameter of $\Phi 1 \mathrm{~mm}$ to insure the full amorphous microstructure. The rod shape sample was cut into small rods with low speed diamond saw (SYJ 160, China). The amorphous characteristic of the sample was confirmed by using X-ray diffraction with a $\mathrm{Cu}$ Ka radiation (XRD, D8 Discovery) within the central plane of the rod shape sample after carefully polish. The ratio of height to radius of the rod samples used for room temperature compressive tests was 2:1. And the compressive tests were taken on materials testing machine (Instron MTS569) at a strain rate of $3 \times 10^{-4} \mathrm{sec}^{-1}$. The fracture morphology after compressing was observed by scanning electron microscopy (SEM, JEOL JSM-6360LV). Prior to nanoindentation test, the cylindrical rods were polished to a mirror finish. The nanoindentation tests were carried out at room temperature in the CSM mode using Agilent G200 Nanomechanical Tester fitted with a Berkovitch diamond tip. The maximum depth of indentation is $1000 \mathrm{~nm}$. A load holding period of $10 \mathrm{~s}$ was introduced at the peak load before unloading. The thermal drift was controlled below $\pm 0.05 \mathrm{~nm} / \mathrm{s}$. A total of 50 indentations were performed to verify the accuracy of the indentation data. 


\section{Results and discussion}

Fig. 1 shows the $\mathrm{XRD}$ patterns of the as cast $\mathrm{Cu}_{29} \mathrm{Zr}_{32} \mathrm{Ti}_{15} \mathrm{Al}_{5} \mathrm{Ni}_{19}$. As it can be seen, only a broad diffraction peak without any detectable sharp diffraction peak corresponding to crystalline phase can be observed, confirmed that the microstructure of the tested sample is fully amorphous.

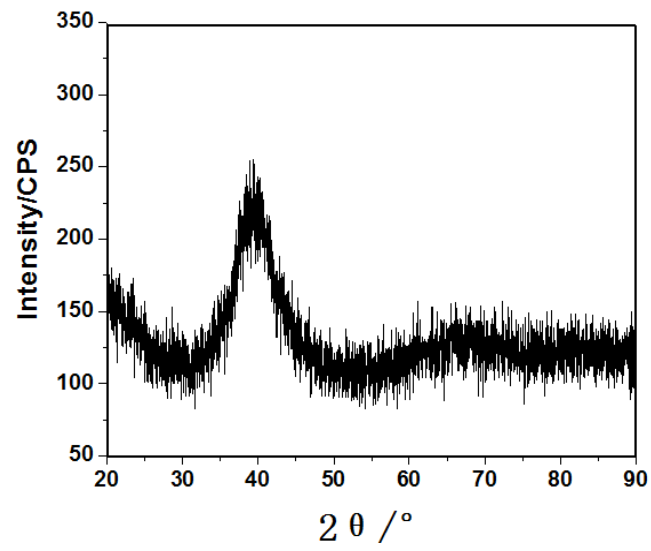

Fig. $1 \mathrm{XRD}$ patterns of the as cast $\mathrm{Cu}_{29} \mathrm{Zr}_{32} \mathrm{Ti}_{15} \mathrm{Al}_{5} \mathrm{Ni}_{19}$ with diameter of $\Phi 1 \mathrm{~mm}$

Fig. 2 shows the compressive stress-strain curves of the glassy rod shape $\mathrm{Cu}_{29} \mathrm{Zr}_{32} \mathrm{Ti}_{15} \mathrm{Al}_{5} \mathrm{Ni}_{19}$. The fracture morphologies of HE-BMG $\mathrm{Cu}_{29} \mathrm{Zr}_{32} \mathrm{Ti}_{15} \mathrm{Al}_{5} \mathrm{Ni}_{19}$ are shown in Fig. 3. From fig.2, the HE-BMG $\mathrm{Cu}_{29} \mathrm{Zr}_{32} \mathrm{Ti}_{15} \mathrm{Al}_{5} \mathrm{Ni}_{19}$ exhibits appreciable yield behavior and plastic deformation. The yield stress is $1673 \mathrm{MPa}$, the total plastic deformation during compression before break is high up to $20 \%$. Obviously, the HE-BMG $\mathrm{Cu}_{29} \mathrm{Zr}_{32} \mathrm{Ti}_{15} \mathrm{Al}_{5} \mathrm{Ni}_{19}$ is of better ductility than many reported BMGs. From Fig.2, the compressive stress-strain curve of HE-BMG clearly illustrates the serrated flow pattern. The occurrence of inhomogeneous plastic flow indicates the formation and propagation of shear bands ${ }^{[9]}$. The shear bands can be observed at the outer surface of the deformed specimen (see Fig.3).

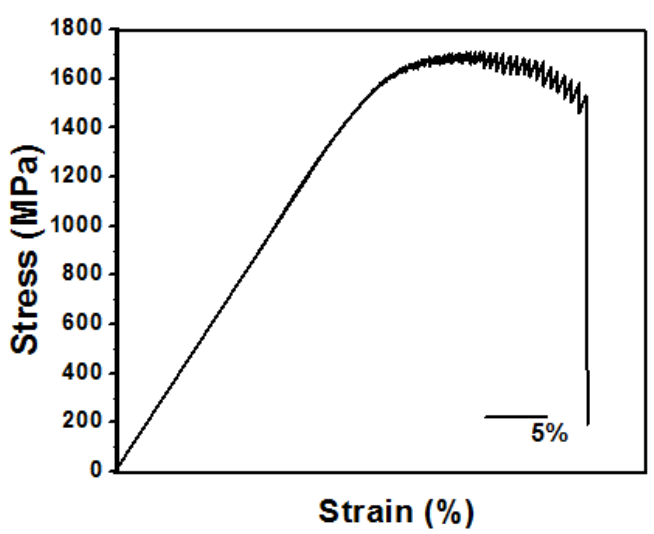

Fig.2 Room temperature compressive stress-strain curves of the glassy rod $\mathrm{Cu}_{29} \mathrm{Zr}_{32} \mathrm{Ti}_{15} \mathrm{Al}_{5} \mathrm{Ni}_{19}$

From fig.3, large amount of branched and intersected shear bands can be found. The magnification of zone I and zone II make it more clearly. As we know, shear bands can carry very large localized plastic strains in compression. So slipping, branching, and intersecting of multiple shear bands thereby enhance the plasticity of HE-BMG. Moreover, uniform vein-like or petal-like structure is found in the fracture surface of HE-BMG (magnification of zone III in Fig.3). The vein pattern morphology is commonly attributed to local change in viscosity near planes of maximum shear stress ${ }^{[2]}$. And the vein like fracture surface of HE-BMG indicates the energy dissipation mechanism being dominated by local plastic flow ${ }^{[10]}$, declining the propagation speed of shear bands and therefore favor improve ductility. 


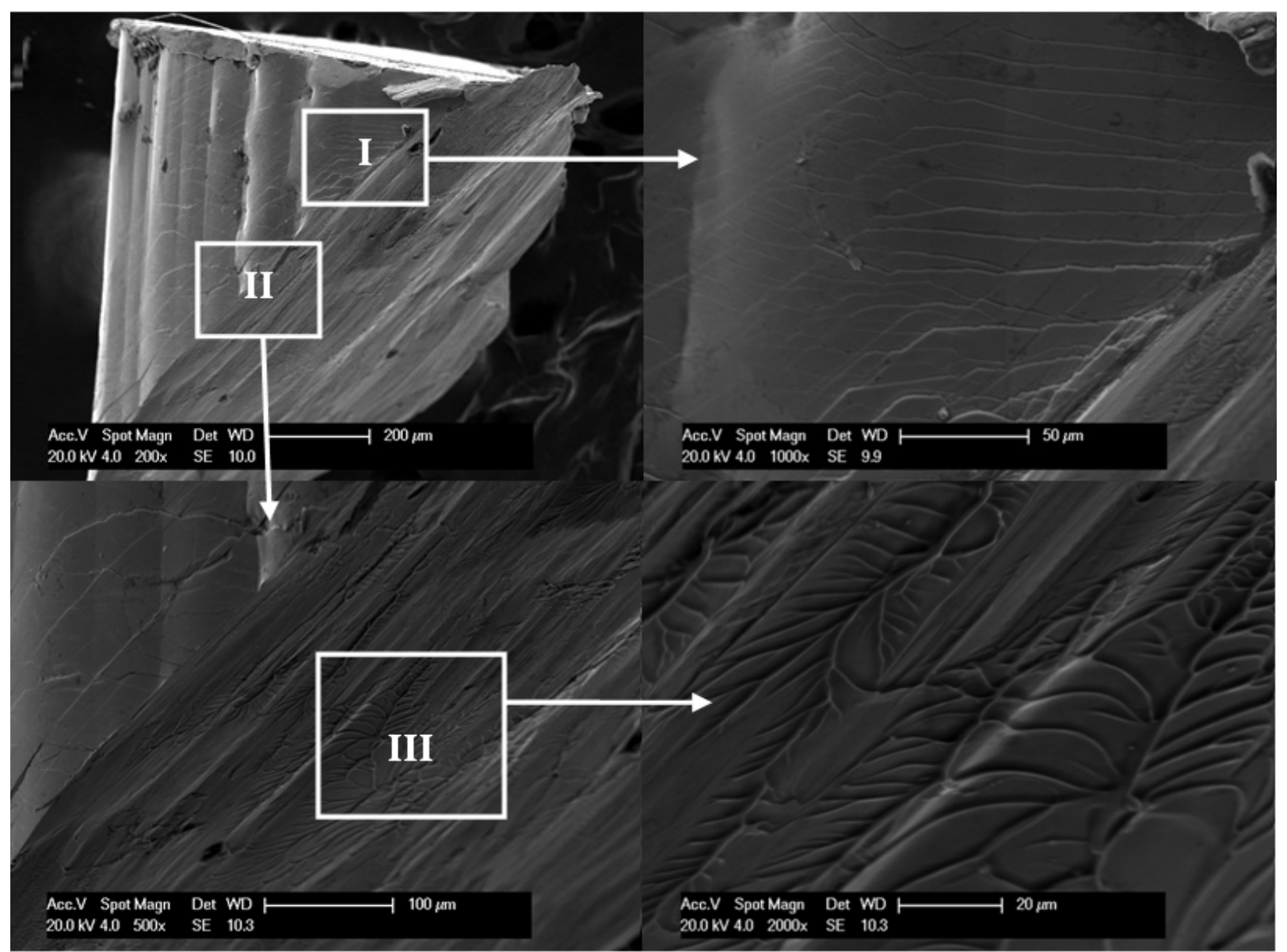

Fig.3 Fracture morphologies of HE-BMG $\mathrm{Cu}_{29} \mathrm{Zr}_{32} \mathrm{Ti}_{15} \mathrm{Al}_{5} \mathrm{Ni}_{19}$

Fig. 4 shows the typical load-displacement $(\mathrm{P}-\mathrm{h})$ indentation curves corresponding to the HE-BMG $\mathrm{Cu}_{29} \mathrm{Zr}_{32} \mathrm{Ti}_{15} \mathrm{Al}_{5} \mathrm{Ni}_{19}$ sample.

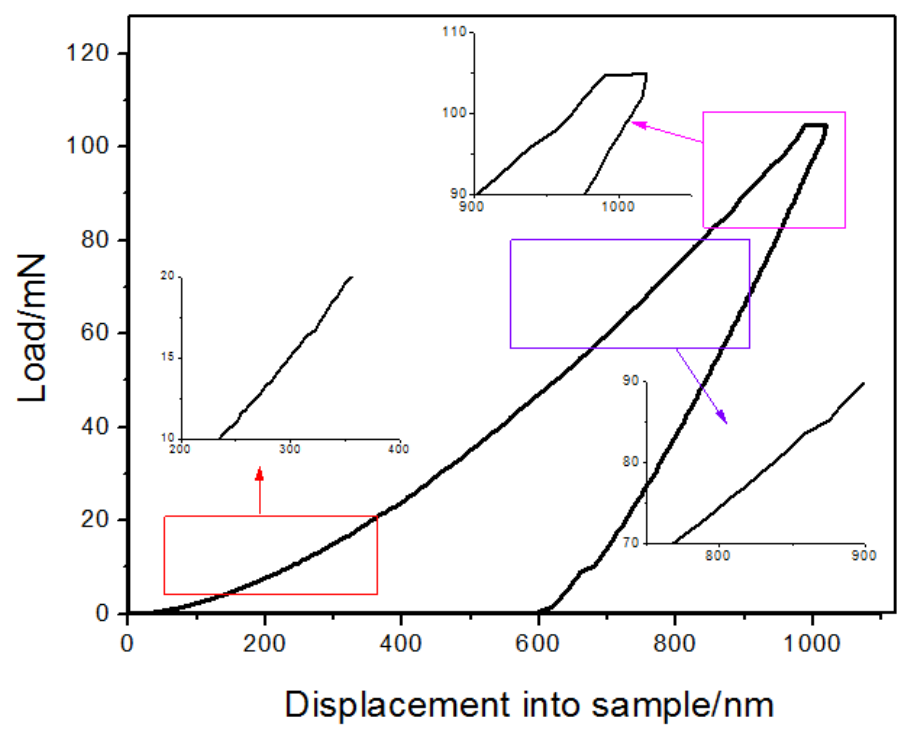

Fig. 4 Typical load-displacement ( $\mathrm{P}-\mathrm{h})$ indentation curves of $\mathrm{HE}-\mathrm{BMG} \mathrm{Cu}_{29} \mathrm{Zr}_{32} \mathrm{Ti}_{15} \mathrm{Al}_{5} \mathrm{Ni}_{19}$

From Fig.4, it can be easily seen that serrated plastic flow also occurs during depth-sensing nanoindentation which is similar to room temperature compressive tests. Multiple steps deformation improves its ability of plastic deformation. The average values of nanohardness and elastic modulus of tested 50 points are $7.29 \mathrm{GPa}$ and $105.4 \mathrm{GPa}$, respectively. 


\section{Summary}

Amorphous $\mathrm{Cu}_{29} \mathrm{Zr}_{32} \mathrm{Ti}_{15} \mathrm{Al}_{5} \mathrm{Ni}_{19}$ with the composition characteristic of high entropy alloy was successfully prepared in a copper mold. It shows a combination of high strength (1673MPa) and excellent ductility under room temperature compression. Particular attention should be pay to that the plastic deformation is high up to $20 \%$ during compression. The nanohardness and elastic modulus of the glassy $\mathrm{Cu}_{29} \mathrm{Zr}_{32} \mathrm{Ti}_{15} \mathrm{Al}_{5} \mathrm{Ni}_{19}$ are $7.29 \mathrm{GPa}$ and $105.4 \mathrm{GPa}$, respectively. Similarly to compression tests, serrated plastic flow also occurs during depth-sensing nanoindentation.

\section{Acknowledgement}

The authors would like to thank for the financial support by the Open Fund of Jiangsu Key Laboratory of Advanced Structural Materials and Application Technology (ASMA201418), Innovation Fund (CKJA201301) and Dr. Special Found (ZKJ201403) of Nanjing Institute of Technology.

\section{References}

[1] A. Takeuchi, N. Chen, T. Wada et al, Alloy design for high-entropy bulk glassy alloys , Procedia Eng. 36(2012)226-234.

[2] S. Guo, C.T. Liu, Phase stability in high entropy alloys: Formation of solid-solution phase or amorphous phase, Prog Nat Sci. 21(2011)433-446.

[3] A. Takeuchi, N. Chen, T. Wada, et al. $\mathrm{Pd}_{20} \mathrm{Pt}_{20} \mathrm{Cu}_{20} \mathrm{Ni}_{20} \mathrm{P}_{20}$ high-entropy alloy as a bulk metallic glass in the centimeter, Intermetallics. 19(2011) 1546-1554.

[4] S. Guo, Q. Hu, C. Ng et al. More than entropy in high-entropy alloys: Forming solid solutions or amorphous phase, Intermatallic. 41(2013)96-103.

[5] H.Y. Ding, K.F. Yao. High entropy $\mathrm{Ti}_{20} \mathrm{Zr}_{20} \mathrm{Cu}_{20} \mathrm{Ni}_{20} \mathrm{Be}_{20}$ bulk metallic glass, J. Non-Cryst Solids. 364(2013)9-12.

[6] X.Q. Gao, K. Zhao, H.B. Ke et al. Hgh mixing entropy bulk metallic glasses J. Non-Cryst Solids ,357(2011)3557-3560.

[7] H. Y. Ding, K.F. Yao, P. Gong et al. A senary TiZrHfCuNiBe high entropy bulk metallic glass with large glass-forming ability, Mater. Lett. 125( 2014)151-153.

[8] J.H. Pi, Y. Pan. Thermodynamic analysis for microstructure of high-entropy alloys, Rare Metal Mat Eng. 42(2013)232-237.

[9] J. Fornell, A. Concustell, S. Suriñach, et al. Yielding and intrinsic plasticity of $\mathrm{Ti}-\mathrm{Zr}-\mathrm{Ni}-\mathrm{Cu}-\mathrm{Be}$ bulk metallic glass, Int J Plasticity. 25(2009)1540-1559.

[10] A.R. Yavari, J. Lewandowski, J. Eckert. Mechanical properties of bulk metallic glasses, Mrs Bulletin. 32(2007) 635-638. 